\title{
INTEGRASI DATA MULTIBEAM BATIMETRI DAN MOSAIK BACKSCATTER UNTUK KLASIFIKASI TIPE SEDIMEN
}

\section{DATA INTEGRATION BATHYMETRY MULTIBEAM AND BACKSCATTER MOSAIC FOR CLASSIFICATION TYPE OF SEDIMEN}

\author{
Anang Prasetia Adi ${ }^{1}$, Henry M Manik ${ }^{2}$, Sri Pujiyati ${ }^{2}$ \\ ${ }^{1}$ Pusat Hidrografi dan Oseanografi, Tentara Nasional Indonesia, Angkatan Laut \\ ${ }^{2}$ Departemen Ilmu dan Teknologi Kelautan, \\ Fakultas Perikanan dan Ilmu Kelautan, Institut Pertanian Bogor \\ Korespondensi: anang@gmail.com, henrymanik@yahoo.com, sripujiyati@yahoo.com
}

\begin{abstract}
The multibeam echo sounder system not only obtained high precision in bathymetry data processing, but also obtaned a high resolution in seabed backscatter strenght data (BS). A number of studies have applied acoustic remote sensing method to classify seabed sediment type with multi-beam backscatter strength data, and obtained better classification results than the traditional sediment sampling method. The objective of this study was to integrating data obtaned from the multibeam echosounder which determined the bathymetry and seabed sediment type classification. This research using bathymetry data survey from multibeam echo sounder Kongsberg EM 2030C in the waters of the Kapuas River, Pontianak, West Borneo. The determination of the bathymetry was done by using the Combined Uncertainty and Bathymetry Estimator (CUBE) method, while determining the sediment type was done by using the Angular Response (ARA) and Sediment Analysis (SAT) method, installed on CARIS Hips and Sips software version 9.0. Results of unsupervised classification there are four types of sediments. The intensity sediment type of gravel range between $-16 \mathrm{~dB}$ to $-13 \mathrm{~dB}$, sand $-22 \mathrm{~dB}$ to $-17 \mathrm{~dB}$, silt $-26 \mathrm{~dB}$ to $-23 \mathrm{~dB}$ and clay $-34 \mathrm{~dB}$ to $-29 \mathrm{~dB}$.
\end{abstract}

Keyword: backscatter, bathymetry, multibeam echosounder, sediment type

\begin{abstract}
ABSTRAK
Sistem multibeam echosounder tidak hanya memperoleh presisi tinggi dalam pengolahan data batimetri saja, tetapi juga mendapatkan resolusi tinggi dalam data backscatter strenght (BS) dasar perairan. Sejumlah penelitian telah menerapkan metode akustik untuk mengklasifikasikan tipe sedimen dasar perairan dengan menggunakan data backscatter, dan hasil klasifikasi yang diperoleh lebih baik daripada sampling sedimen secara tradisional. Tujuan penelitian ini untuk mengintegrasikan hasil data multibeam echosounder dalam penentuan batimetri dan pengklasifikasian tipe sedimen dasar perairan.Penelitian menggunakan data survei batimetri multibeam echosounder Kongsbergs EM 2040C di Sungai Kapuas Pontianak, Kalimantan Barat. Penentuan batimetri menggunakan metode Combined Uncertainty and Bathymetry Estimator (CUBE), sedangkan klasifikasi tipe sedimen menggunakan metode Angular Response (ARA) dan Sediment Analysis (SAT) yang semuanya tertanam dalam software Caris Hips and Ships versi 9.0. Hasil klasifikasi tipe sedimen secara unsupervised terdapat empat tipe sedimen. Nilai intensitas tipe sedimen kerikil (gravel) berkisar antara $-16 \mathrm{~dB}$ hingga $-13 \mathrm{~dB}$, pasir (sand) berkisar antara $-22 \mathrm{~dB}$ hingga $-17 \mathrm{~dB}$, lumpur (silt) antara $-26 \mathrm{~dB}$ hingga -23 $\mathrm{dB}$ dan lempung (clay) berkisar antara $-34 \mathrm{~dB}$ hingga $-29 \mathrm{~dB}$.
\end{abstract}

Kata kunci: backscatter, batimetri, multibeam echosounder, tipe sedimen 


\section{PENDAHULUAN}

\section{Latar belakang}

Multibeam echosounder (MBES) merupakan peralatan akustik yang secara intensif sering digunakan dalam pemetaan dasar perairan, terutama karena teknologi ini memiliki kemampuan lebih yaitu cakupan luas dan resolusi tinggi untuk akuisisi data batimetri (Anderson et al. 2008). Pemetaan dasar perairan menjadi sangat penting karena memberikan informasi secara detail dan akurat mengenai topografi dasar perairan. Informasi ini sangat diperlukan dalam berbagai aplikasi kelautan seperti pembuatan peta navigasi guna menjamin keamanan dan keselamatan lalu lintas kapal, pencarian kapal tenggelam dan lain sebagainya.

Teknologi multibeam echosounder merupakan perpanjangan dari teknologi singlebeam echosounder yang hanya memancarkan satu beam secara vertikal ke dasar perairan, sedangkan multibeam mampu mentransmisikan beratusratus beam ke dasar perairan dan pola pancarannya melebar dan melintang terhadap badan kapal (Lurton 2010). Setiap beam yang dipancarkan akan mendapatkan satu titik kedalaman hingga jika titik-titik kedalaman tersebut dihubungkan akan membentuk profil topografinya. Ada dua tipe dataset yang dihasilkan multibeam echosounder untuk mendukung pemetaan dasar perairan yaitu data batimetri dan mosaik backscatter.

MBES batimetri merupakan proses pemetaan kedalaman perairan yang dinyatakan dalam angka kedalaman atau kontur kedalaman yang diukur terhadap datum vertikal. Batimetri (dari bahasa Yunani: berarti "kedalaman" dan "ukuran") adalah ilmu yang mempelajari kedalaman di bawah air dan studi tentang tiga dimensi dasar perairan. Sebuah peta batimetri umumnya menampilkan relief dasar perairan dengan garis-garis kontur (contour lines) yang disebut kontur kedalaman (depth contours atau isobath). MBES batimetri merupakan proses pemetaan kedalaman perairan yang dinyatakan dalam angka kedalaman atau kontur kedalaman yang diukur terhadap datum vertikal. Batimetri (dari bahasa Yunani: berarti "kedalaman" dan "ukuran") adalah ilmu yang mempelajari kedalaman di bawah air dan studi tentang tiga dimensi dasar perairan. Sebuah peta batimetri umumnya menampilkan relief dasar perairan dengan garis-garis kontur (contour lines) yang disebut kontur kedalaman (depth contours atau isobath).

MBES backscatter adalah intensitas akustik yang dipantulkan dasar perairan menggunakan fungsi respon sudut pancaran (angular response), hasil yang didapat digambarkan dalam kurva hubungan antara nilai intensitas dan respon sudut pancaran. Tiap tipe sedimen dasar perairan yang berbeda biasanya menunjukkan tingkat intensitas yang berbeda. Variasi gambaran ini dipengaruhi oleh respon sudut pancaran dari sinyal akustik dan perubahan geografi tipe sedimen dasar perairan (Hasan et al. 2014). Analisis terhadap amplitudo dari gelombang suara yang kembali memungkinkan untuk mengekstrak informasi mengenai struktur dan kekerasan dari dasar perairan, yang digunakan untuk mengklasifikasi tipe sedimen. Sinyal kuat yang kembali menunjukan permukaan dasar perairan yang keras (rock, graveı) dan sinyal lemah yang kembali menunjukan permukaan yang lebih halus (silt, clay). Hal tersebut karena semakin besar impedansi suatu medium semakin besar pula koefisien pantulannya.

Sungai Kapuas merupakan sungai yang membelah kota Pontianak dan sampai saat ini masih menjadi urat nadi dan jalur utama untuk angkutan daerah pedalaman bagi kehidupan masyarakat di sepanjang aliran sungai ini. Sebagai prasarana transportasi alam yang murah, Sungai Kapuas digunakan untuk menghubungkan daerah satu ke daerah lain di wilayah Kalimantan Barat (Jumarang et al. 2012). Pelabuhan Pontianak merupakan salah satu pelabuhan yang ramai di wilayah Indonesia karena letak wilayahnya sangat strategis yang berbatasan dan berhadapan langsung dengan negara Malaysia dan Singapura (Dephub Pelabuhan Pontianak 2010). Wilayah ini mempunyai nilai ekonomis yang sangat baik, sehingga untuk menjamin keselamatan pelayaran dari kapal-kapal yang keluar masuk Pelabuhan Pontianak menjadi prioritas utama. Adanya informasi mengenai batimetri dan jenis tipe sedimen dapat digunakan sebagai data pendukung awal kegiatan survei pengerukan (dredging) pada area yang mengalami kedangkalan, serta dapat digunakan juga sebagai informasi awal dalam kegiatan survei rekayasa engineering semisal pembangunan dermaga untuk kapal-kapal perintis, survei rute pipa dan kabel bawah perairan. Tujuan penelitian ini adalah untuk mengintegrasikan hasil data yang di dapat dari multibeam echosounder (data batimetri dan backscatter) yang meliputi: Mengklasifikasi tipe sedimen dasar perairan menggunakan metode Angular Response Analysis (ARA) dan Sediment Analysis Tool (SAT); Menghubungkan nilai hambur balik dengan tipe sedimen. Manfaat penelitian ini diharapkan mampu memberikan informasi pemetaan dasar perairan yang lebih lengkap dan akurat berdasarkan data batimetri dan backscatter, guna mendukung pimpinan ataupun instansi terkait sebagai bahan pertimbangan pengambilan keputusan atau pembuatan kebijakan dalam pengelolaan Sungai Kapuas.

\section{METODE PENELITIAN}

Penelitian ini menggunakan data hasil survei batimetri di sungai Kapuas Pontianak, Kalimantan Barat pada tanggal 3-4 Nopember 2015 menggunakan teknologi 
multibeam echosounder. Rata-rata nilai kedalaman berkisar antara 10 - 15 meter. Data dan informasi dalam penelitian ini diperoleh melalui survei akustik untuk keperluan batimetri yang menggunakan peralatan multibeam echosounder Kongsberg EM 2040C di Sungai Kapuas Pontianak, Kalimantan Barat yang diperoleh dari Dinas Hidro-Oseanografi TNI AL. Pemilihan lokasi penelitian diusahakan memiliki batimetri yang unik dan tipe sedimen yang bervariasi, sehingga hasil intensitas akustik yang didapat bisa mewakili jenis sedimen yang berbeda.

Pelaksanaan pengambilan data penelitian ini menggunakan kapal perum (boat sounding) dengan dimensi $16 \times 2.7$ meter. Spesifikasi teknis untuk spasi jarak antar lajur berkisar \pm 30 meter. Jumlah lajur utama survei yang digunakan dalam penelitian sebanyak 11 lajur dan lajur silang (cross) sebanyak 3 lajur. Lokasi area penelitian, transek lajur survei, lokasi pengambilan data CTD dan titik sampel pengambilan data sedimen ditunjukkan pada Gambar 1.

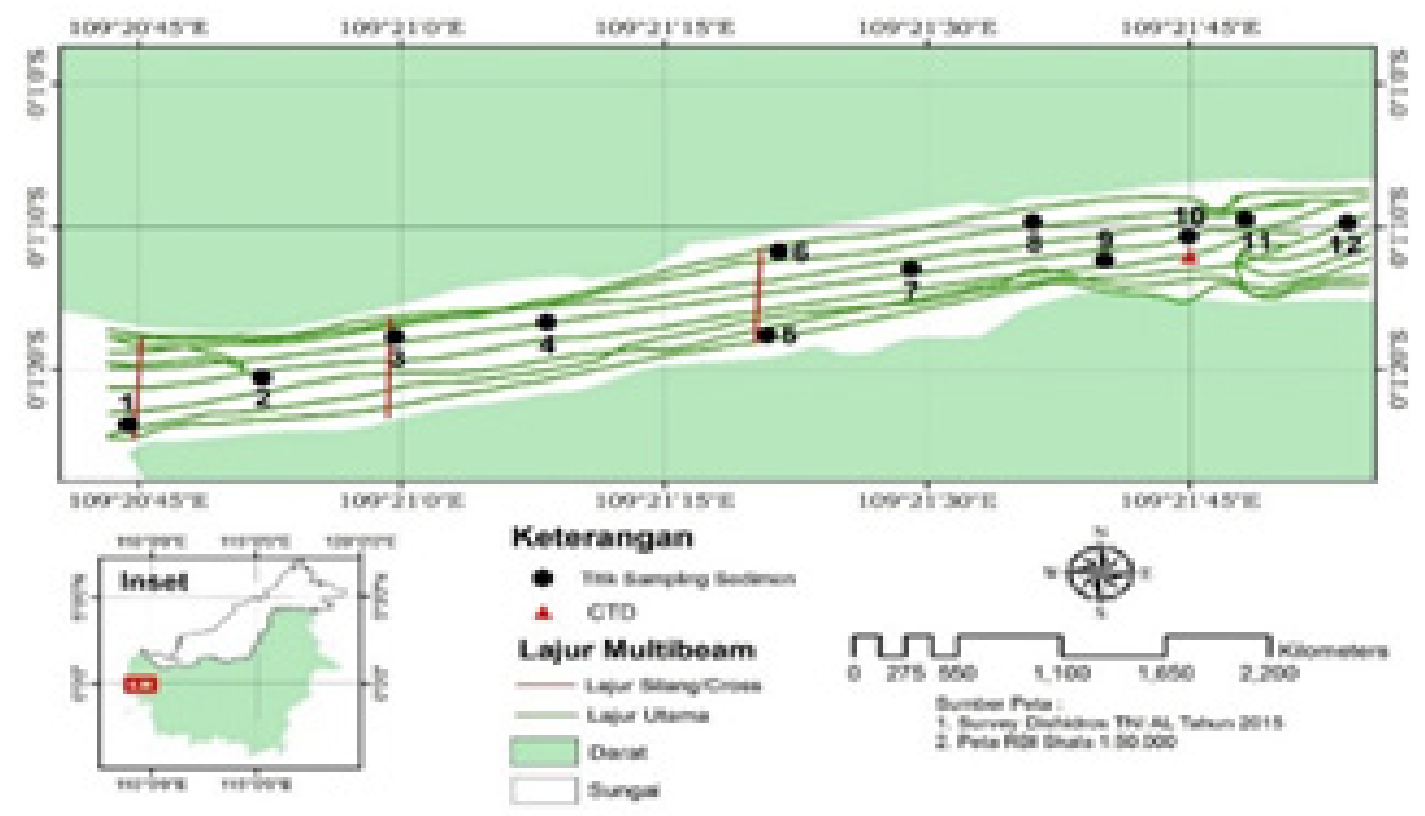

Gambar 1. Lokasi area penelitian, transek lajur survei, lokasi pengambilan data CTD dan titik sampel sedimen

\section{Akuisisi data akustik}

Penelitian ini menggunakan multibeam echosounder Kongsberg EM 2040C yang memiliki kemampuan dual swath dan dilengkapi dengan stabiliser pitch, roll dan yaw. Multibeam ini memiliki 400 beam dengan sudut bukaan sebesar $1.3^{\circ}$ untuk tiap beam. Untuk frekuensi $300 \mathrm{kHz}$, sistem ini dapat digunakan pada perairan dangkal dan perairan dengan kedalaman medium yaitu tidak melebihi dari 450 meter dan memiliki kemampuan untuk memetakan wilayah perairan secara luas dengan lebar sapuan mencapai $130^{\circ}$ (Manual Book Operating System Kongsberg EM 2040C).

MBES dipasang dikapal perum dengan menggunakan software navigasi Automatic Data Logging (ADL) HydroPro dan untuk akuisisi data menggunakan software SIS (Seafloor Information System). Penentuan posisi pemeruman digunakan DGPS Veripos yang memiliki kesalahan horisontal 0.13 meter dan kesalahan vertikal 0.32 meter pada tingkat kepercayaan 95\%. Untuk sensor gerak (motion sensor) menggunakan Teledyne TSS DMS-05yang memiliki akurasi pitch dan roll sebesar $0.05^{\circ}$. Data sound velocity profile (svp) didapatkan dengan menurunkan CTD AML Oceanographic dan pengambilan data pasang surut menggunakan peralatan Thalimedes.

\section{Pengolahan data batimetri}

Survei batimetri adalah bagian dari kegiatan survei hidrografi yang bertujuan untuk mendapatkan nilai kedalaman dan konfigurasi dasar sungai berdasarkan analisis profil kedalaman yang didapat dari hasil pemeruman (sounding). Survei batimetri dengan menggunakan peralatan multibeam akan menghasilkan pemetaan batimetri sungai, yang mana pemetaan ini merupakan hasil dari serangkaian proses meliputi koreksi alat, koreksi oseanografi, 
filtering, gridding dan interpolation yang semuanya terangkum dalam metode CUBE (Combined Urcertainty and Bathymetry Estimator).

Survei batimetri menggunakan multibeam akan dapat mempersingkat waktu pelaksanaan survei, namun dalam pelaksanaanya perlu diperhatikan walaupun menggunakan teknologi yang lebih modern bagaimanapun tidak menjanjikan perolehan data yang berkualitas serta bebas dari selisih kasar bagi pengukuran kedalaman. Oleh karena itu untuk mendapatkan data batimetri sungai yang akurat memerlukan kalibrasi yang sangat kompleks untuk menentukankualitasalat-alatukurtermasuk alat multibeam dalam penggunaannya serta hasil batimetri yang didapat harus dihitung batas toleransi kesalahannya (Geoscience Australia 2013). Pengolahan raw data multibeam echosounder dengan menggunakan software Caris akan melalui beberapa tahapan seperti yang dijelaskan pada Gambar 2 (Training module Caris Hips \& Sips 9.0, 2014).

\section{Pengolahan data backscatter}

Pengolahan data multibeam

backscatter menggunakan algoritma Geocoder yang diciptakan oleh Dr. Luciano Fonseca dan dilisensi oleh CARIS melalui Universitas New Hampshire. Algoritma ini dikembangkan oleh Fonseca \& Calder pada tahun 2005, dilanjutkan penyempurnaan metode Angular Response Analysis oleh Fonseca \& Mayer pada tahun 2007 (Tutorial module Caris Hips \& Sips 9.0, 2014). Implementasi geocoder digunakan untuk memproses dan menganalisa data backscatter, proses geobars, pembuatan mosaik dan mengestimasi ukuran butir tipe sedimen berdasar sudut respon (Dufek 2012).

Pengolahan data multibeam backscatter menggunakan geocoder merupakan tahapan lanjutan setelah pengolahan CUBE Surface data batimetri, sehingga bisa dipastikan bahwa data yang digunakan sudah terkoreksi dengan baik (MacDonald et al. 2008). Pengolahan ini difokuskan pada tiga hal utama yaitu proses geobars, pembuatan mosaik backscatter dan analisa tipe sedimen, seperti yang dijelaskan pada diagram alir pengolahan data multibeam backscatter pada Gambar 3.

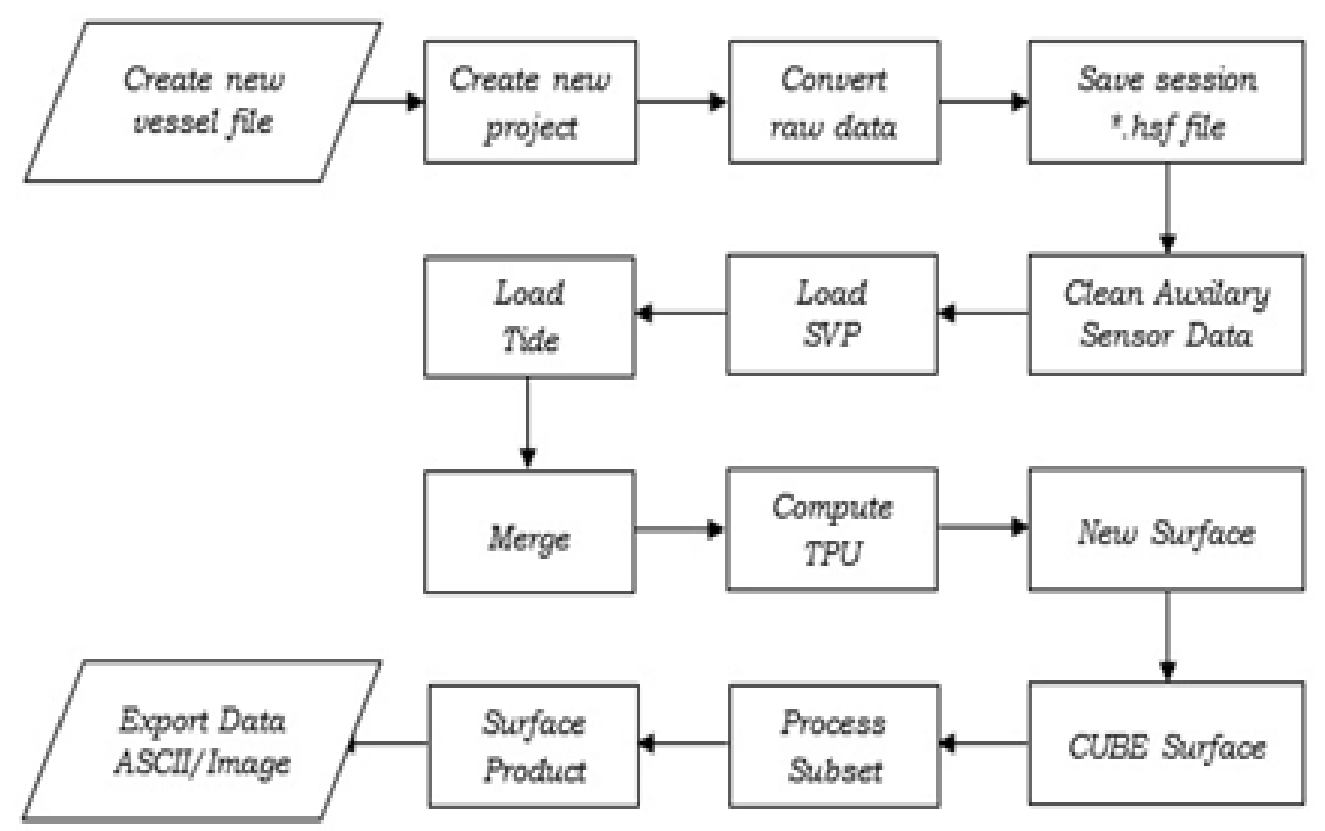

Gambar 2. Diagram alir pengolahan data multibeam batimetri menggunakan software Caris Hips \& Sips 9.0 


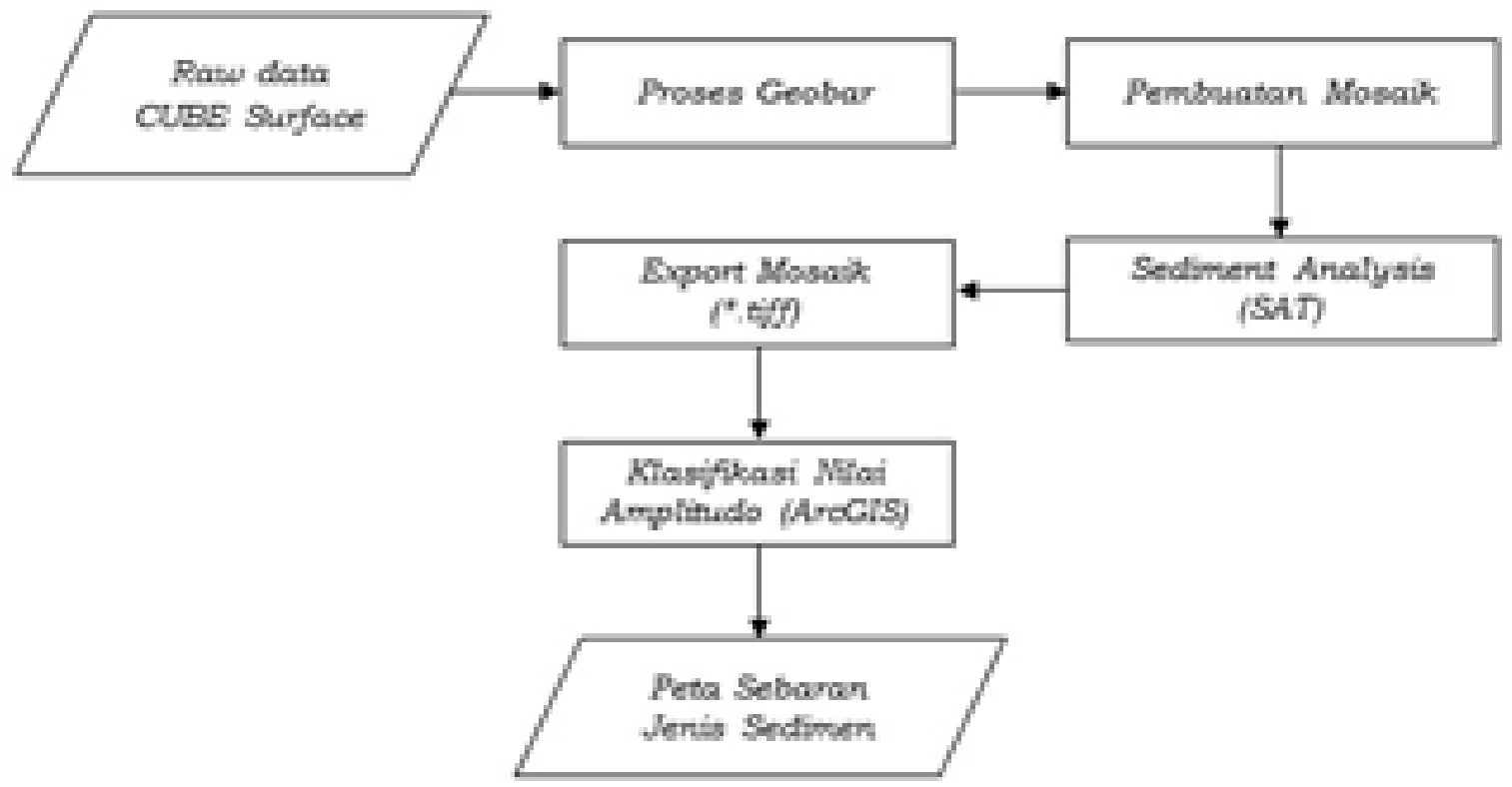

Gambar 3. Diagram alir pengolahan data multibeam backscatter menggunakan software Caris Hips \& Sips 9.0

\section{HASIL DAN PEMBAHASAN}

\section{Profil batimetri}

Hasil pengolahan data batimetri menunjukkan nilai kedalaman sungai berkisar antara 0.04 hingga 15.60 meter, dengan komposisi untuk kedalaman kurang dari 5 meter ditunjukkan pada sisi utara dan selatan sungai. Kedalaman rata-rata di sungai didominasi kedalaman berkisar antara 9 hingga 10 meter, untuk kedalaman lebih dari 15 meter ditunjukkan pada sisi barat Sungai Kapuas yang berdekatan dengan muara. Pengambilan data batimetri di sisi utara dan selatan sungai dilakukan pada saat pasang tertinggi, sehingga didapatkan kontur nol nya.

Pengolahan data batimetri menggunakan software Caris dapat menampilkan secara langsung hasil quality control report (QC) dan statistik data batimetri. Hasil QC menunjukkan bahwa tingkat ketelitian data batimetri menunjukkan data batimetri di lokasi termasuk dalam orde khusus (special order). Hasil pengolahan batimetri di Sungai Kapuas, Pontianak ditunjukkan pada Gambar 4.

\section{Klasifikasi tipe sedimen}

Hasil klasifikasi tipe sedimen dengan menggunakan metode ARA dan SAT di 12 titik yang posisinya sama dengan pengambilan contoh fisik sedimen secara in-situ didapatkan nilai intensitas, ukuran butir (dalam phi dan $\mathrm{mm}$ ) serta jenis tipe sedimennya (Tabel 1). Referensi klasifikasi ini mengacu pada klasifikasi Wentworth (1992), yang mana klasifikasi ini menunjukkan rentang umum ukuran butir bisa dalam satuan phi ataupun milimeter.

Hasil pengolahan analisa sedimen, mosaik backscatter dan kurva nilai intensitas di 12 (dua belas) diproses secara keseluruhan. Hasil pengolahan diwakili pada titik sampel 1, seperti yang ditunjukkan pada Gambar 5.

Secara keseluruhan hasil klasifikasi tipe sedimen di Sungai Kapuas Pontianak menggunakan metode ARA dan SAT didapatkan hasil untuk tipe sedimen pasir halus (fine sand) berkisar -17.038 dB (pada titik sampel 1), pasir sangat halus (very fine sana) berkisar -20.196 dB hingga - 19.150 dB (pada titik sampel 4 dan 12). Sedangkan untuk tipe sedimen lumpur kasar (coarse silt) berkisar $-22.073 \mathrm{~dB}$ hingga $-21.134 \mathrm{~dB}$ (pada titik sampel 5, 7, 8, dan 11), lumpur sedang (medium silt) berkisar -23.233 dB hingga -22.966 dB (pada titik sampel 2, 3, 6 dan 9), lumpur halus (fine silt) berkisar -25.832 dB (pada titik sampel 10). Hasil klasifikasi tipe sedimen di Sungai Kapuas, Pontianak ditunjukkan pada Gambar 6.

\section{Hubungan nilai intensitas dengan tipe sedimen}

Grafik yang pertama (garis berwana biru) yang dihasilkan dari pengolahan data backscatter menggunakan metode ARA dan SAT dibuat koefesien korelasinya. Hasil yang didapatkan memiliki persamaan SS (dB) = 62.489(x) - 24.891 (Gambar 7). Berdasarkan grafik pertama tersebut menunjukkan hubungan antara dua variabel relatif tinggi dengan melihat nilai R2 sebesar 0.88 , hal ini menyatakan bahwa semakin bertambahnya ukuran butiran maka akan berpengaruh terhadap nilai intensitas yang dihasilkan. 
Sumbu x sebagai ukuran butiran ( $\mathrm{mm}$ ) dan sumbu y sebagai nilai intensitas (dB).

Sedangkan pada grafik yang kedua (garis berwarna merah) merupakan hasil hubungan nilai intensitas dengan rata-rata ukuran butiran secara in-situ yang memiliki persamaan SS $(\mathrm{dB})=33.14(\mathrm{x})-26.71$ Pernyataan ini menyatakan bahwa semakin bertambahnya nilai ukuran butiran maka akan berpengaruh terhadap nilai SS yang dihasilkan, meskipun hubungan antara dua variable tidak terlalu tinggi dengan melihat nilai R2 sebesar 0.58.

Hal ini dinyatakan oleh Stanic et al. (1989) nilai hambur balik yang dihasilkan dari empat tipe sedimen seperti lempung, lumpur, pasir dan kerikil menunjukkan korelasi dengan ukuran butiran. Pernyataan yang sama juga dijelaskan oleh Pujiyati (2008) bahwa nilai hambur balik dipengaruhi oleh ukuran partikel. Selain ukuran partikel, nilai hambur balik dasar perairan dapat diduga adanya pengaruh dari faktor lain seperti porositas, kandungan zat organik dan biota yang berada dalam sedimen. Hal lain yang mempengaruhi adalah dari peralatan multibeam itu sendiri, untuk klasifikasi tipe sedimen dasar perairan menggunakan metode ARA dan SAT tidak bisa menggunakan seluruh daripada lebar sapuan beam (swath beam) akan tetapi hanya bisa menggunakan maksimal setengah daripada lebar sapuan (Dufek 2012).

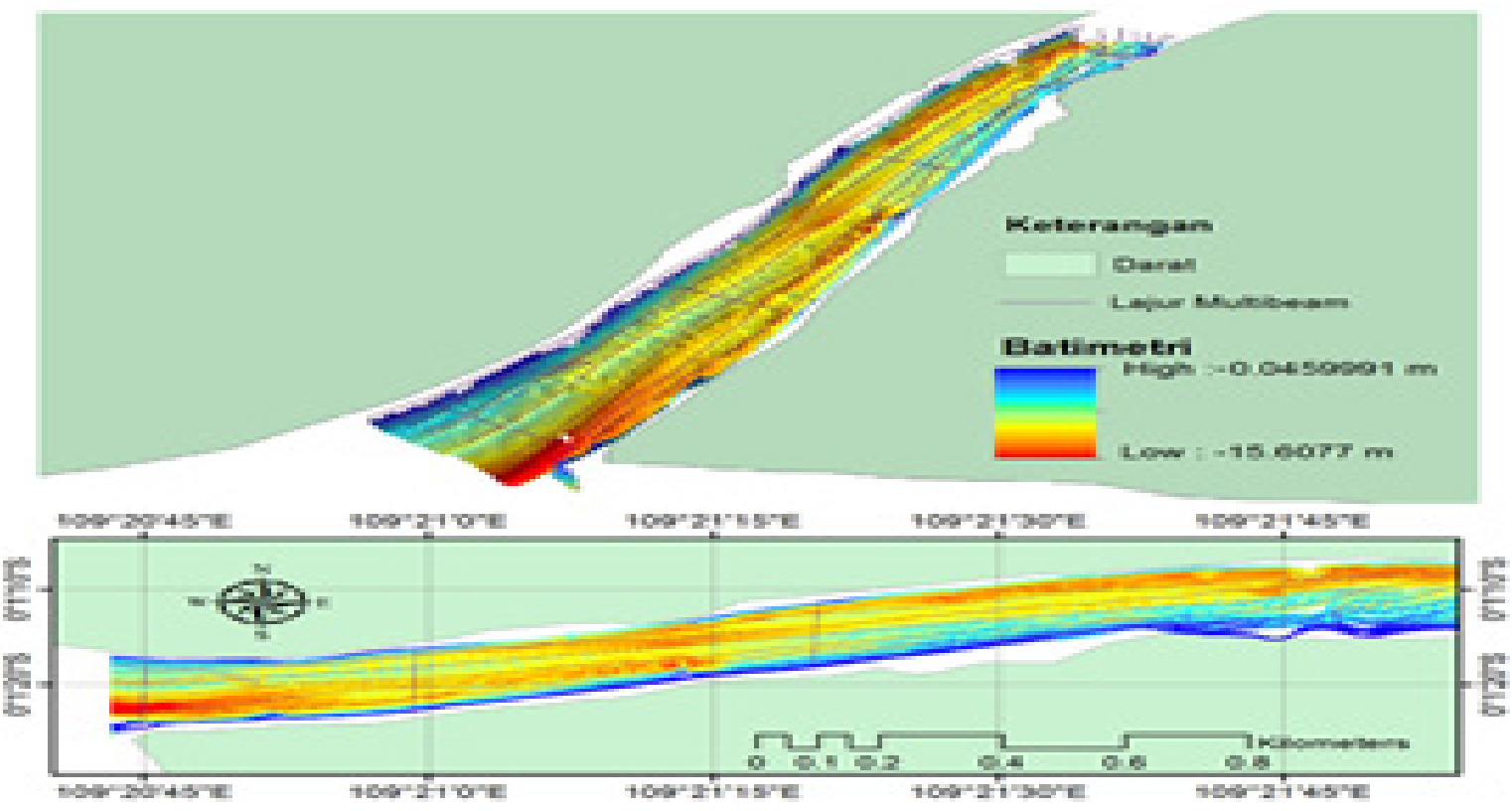

Gambar 4. Profil batimetri di area penelitian

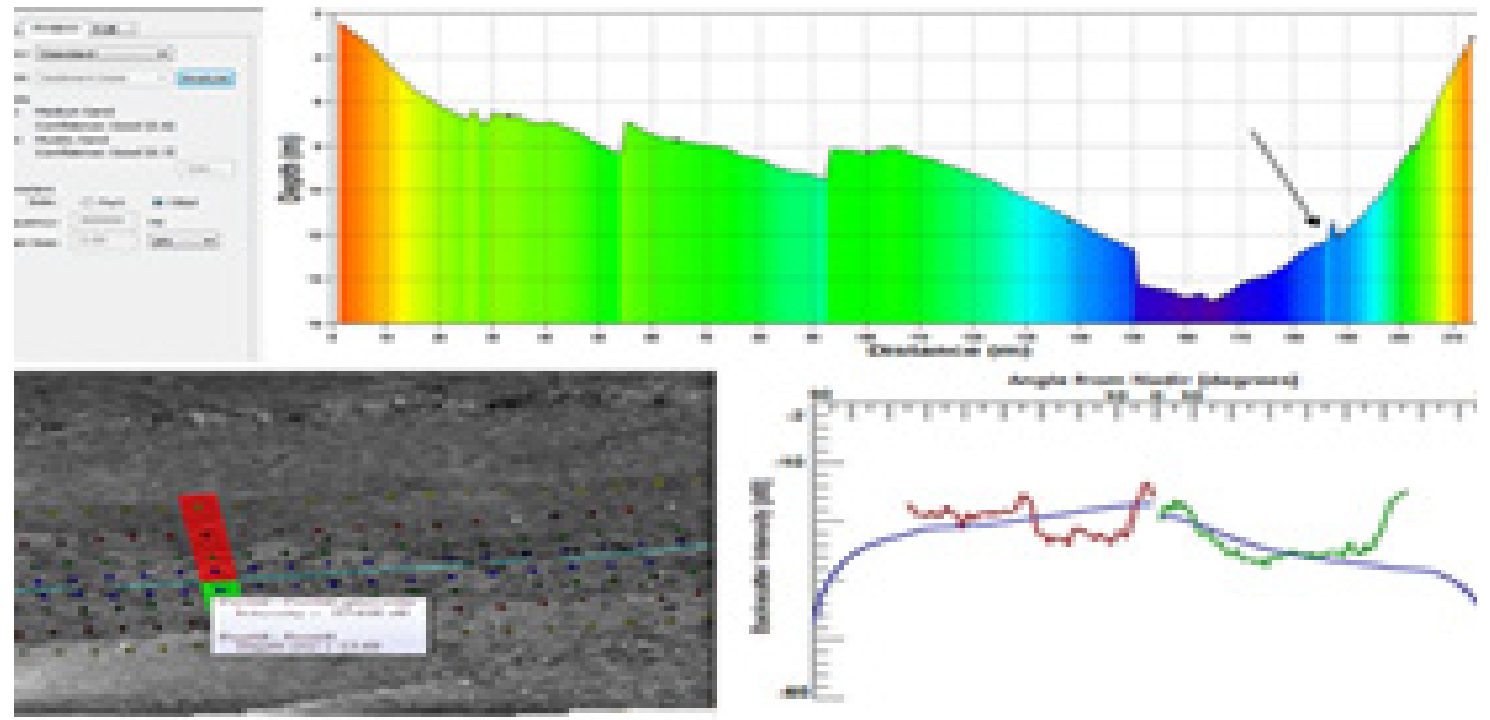

Gambar 5. Hasil klasifikasi tipe sedimen menggunakan metode ARA dan SAT 
Tabel 2. Nama lokal dan nama ilmiah hasil tangkapan beserta frekuensi tertangkap

\begin{tabular}{|c|c|c|c|c|c|c|}
\hline Titik & Posisi & Depth (m) & $\begin{array}{l}\text { Intensitas } \\
\text { (dB) }\end{array}$ & phi & $\mathbf{m m}$ & Tipe sedimen \\
\hline 1 & $\begin{array}{r}109^{\circ} 20^{\prime} 45^{\prime \prime} \mathrm{BT} \\
0^{\circ} 01^{\prime} 24 " \mathrm{LS}\end{array}$ & 13.5 & -17.038 & 2.82 & 0.14 & fine sand \\
\hline 2 & $\begin{array}{r}109^{\circ} 20^{\prime} 52^{\prime \prime} \mathrm{BT} \\
0^{\circ} 01^{\prime} 20^{\prime \prime} \mathrm{LS}\end{array}$ & 8.8 & -23.231 & 5.11 & 0.03 & medium silt \\
\hline 3 & $\begin{array}{r}109^{\circ} 21^{\prime}, 00^{\prime \prime} \mathrm{BT} \\
0^{\circ} 01^{\prime} 18^{\prime \prime} \mathrm{LS}\end{array}$ & 9.3 & -23.233 & 5.11 & 0.03 & medium silt \\
\hline 4 & $\begin{array}{r}109^{\circ} 21^{\prime}, 10^{\prime \prime} \mathrm{BT} \\
0^{\circ} 01^{\prime} 17^{\prime \prime} \mathrm{LS}\end{array}$ & 9.7 & -20.196 & 3.98 & 0.06 & very fine sand \\
\hline 5 & $\begin{array}{r}109^{\circ} 21^{\prime} 21^{\prime \prime} \mathrm{BT} \\
0^{\circ} 01^{\prime} 18^{\prime \prime} \mathrm{LS}\end{array}$ & 8.1 & -21.825 & 4.59 & 0.04 & coarse silt \\
\hline 6 & $\begin{array}{r}109^{\circ} 21^{\prime}, 19 " \mathrm{BT} \\
0^{\circ} 01^{\prime} 12 " 12 \mathrm{LS}\end{array}$ & 10.2 & -22.966 & 5.01 & 0.03 & medium silt \\
\hline 7 & $\begin{array}{r}109^{\circ} 21^{\prime} 27^{\prime \prime} \mathrm{BT} \\
0^{\circ} 01^{\prime} 13^{\prime \prime} \mathrm{LS}\end{array}$ & 10.4 & -21.735 & 4.55 & 0.04 & coarse silt \\
\hline 8 & $\begin{array}{r}109^{\circ} 21^{\prime} 32^{\prime \prime} \mathrm{BT} \\
0^{\circ} 011^{\prime} 10^{\prime \prime} \mathrm{LS}\end{array}$ & 10.3 & -21.134 & 4.33 & 0.05 & coarse silt \\
\hline 9 & $\begin{array}{r}109^{\circ} 21^{\prime} 36^{\prime \prime} \mathrm{BT} \\
0^{\circ} 01^{\prime} 12 ” \mathrm{LS}\end{array}$ & 10.6 & -23.142 & 5.07 & 0.03 & medium silt \\
\hline 10 & $\begin{array}{r}109^{\circ} 21^{\prime} 45^{\prime \prime} \mathrm{BT} \\
0^{\circ} 01^{\prime} 11^{\prime \prime} \mathrm{LS}\end{array}$ & 8.8 & -25.832 & 6.07 & 0.01 & fine silt \\
\hline 11 & $\begin{array}{r}109^{\circ} 21^{\prime} 48^{\prime \prime} \mathrm{BT} \\
0^{\circ} 01^{\prime} \text { '09" LS }\end{array}$ & 11.4 & -22.073 & 4.68 & 0.04 & coarse silt \\
\hline 12 & $\begin{array}{r}109^{\circ} 21^{\prime} 54^{\prime \prime} \mathrm{BT} \\
0^{\circ} 01^{\prime} 10^{\prime \prime} \mathrm{LS}\end{array}$ & 9.5 & -19.150 & 3.60 & 0.08 & very fine sand \\
\hline
\end{tabular}

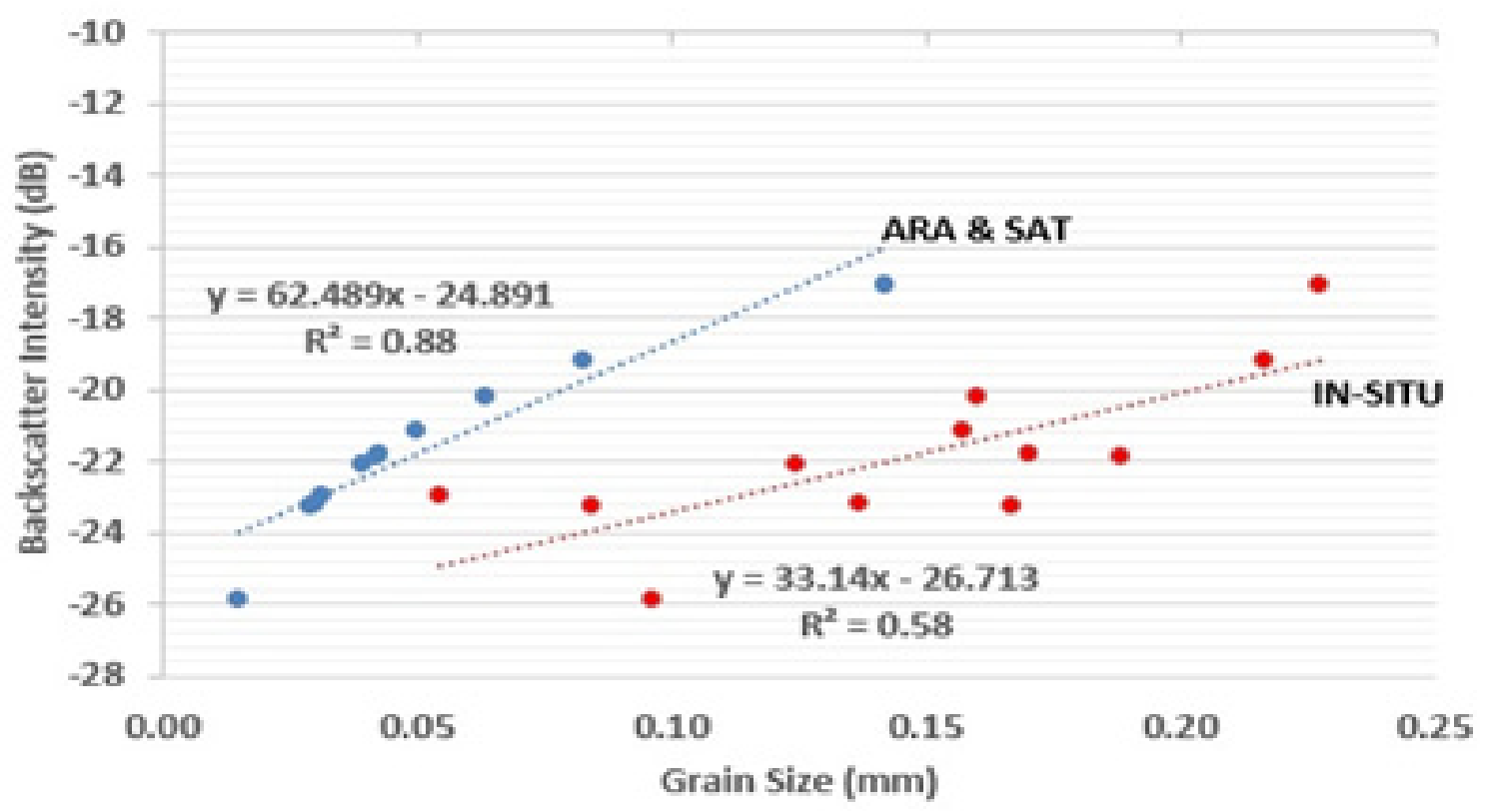

Gambar 7. Hubungan nilai intensitas (dB) dan ukuran butir $(\mathrm{mm})$, menggunakan metode ARA dan SAT (garis biru) dan secara in-situ (garis merah) 


\section{KESIMPULAN}

Klasifikasi tipe sedimen didapatkan sedimen pasir, lumpur berpasir, dan lumpur. Berdasarkan nilai intensitas untuk tipe sedimen pasir (sand) -19.15 dB hingga -17.03 dB pada kedalaman 9.5 meter, lumpur berpasir (sandy silt) -23.23 $\mathrm{dB}$ hingga $-21.13 \mathrm{~dB}$ pada kedalaman 10.3 meter, dan lumpur (silt) -28.00 dB hingga $-25.83 \mathrm{~dB}$ pada kedalaman 8.8 meter. Hubungan atau korelasi antara nilai intensitas (dB) dan ukuran butiran (mm) hasil menggunakan metode ARA dan SAT didapatkan nilai R2 sebesar 0.88, dan korelasi nilai intensitas dan ukuran butiran secara in-situ didapatkan nilai R2 sebesar 0.58 .

\section{DAFTAR PUSTAKA}

Anderson JT, Holliday DV, Kloser R, Reid DG, Simrad Y. 2008. Acoustic seabed classification: Current practice and future directions. ICES J.Mar.Sci, 5: 1004-1011.

Dephub. Pelabuhan Pontianak. 2010. Pelabuhan pontianak. http:// www.dephub. go.id./pelabuhan/ pontianak/ (15 Mei 2014).

Dufek T. 2012. Backscatter analysis of multibeam sonar data in the area of the valvadia fracture zone using Geocoder in CARIS HIPS \& SIPS and IVS 3D Fledermus. Master Thesis. University Hamburg.

Fonseca L. Calder B. 2005. Geocoder: an efficient backscatter map constructor. Proceedings of the U.S. Hydrographic Conference 2005, San Diego, C.A.

Fonseca L, Mayer L. 2007. Remote estimation of surficial seafloor properties through the application angular range Analysis to multibeam sonar data. Mar Geophys Res, 28: 119-126.

Geoscience Australia Record. 2013/33. Standart operation procedure for a multibeam survey.

Hasan C, Ierodiaconou D, Laurenson L, Schimel A. 2014. Integrating Multibeam Backscatter Angular Response, Mosaic and Bathymetry Data for Benthic Habitat Mapping. Victoria, Australia. Plos one 9(5):
Jumarang MI, Muliadi NS. Ningsih, Hadi, S. 2012. Perubahan Dasar Perairan Estuari Sungai Kapuas Kalbar. Jurnal Ilmu FIsika Indonesia 1(1).

Lurton X. 2010 : An introduction to underwater acoustics principles and application. 2nd Edition, Springer, Berlin Heidelberg.

MacDonald A, Collins C. 2008. Taking Geocoder to Work. Proceedings of the Shallow Survey Conference 2008, Portsmouth, N.H.

Manik HM, Furusawa M, Amakasu K. 2006. Measurement of sea bottom surface backscattering strength byquantitative echo sounder. Department of Ocean Science, Tokyo University of Marine Science and Technology, 4-5-7 Konan, Minato-ku, Tokyo 108-8477, Japan

Manik HM. 2010. Pengukuran akustik scattering strength dasar perairan dan identifikasi habitat ikan dengan echosounder. Seminar Nasional Perikanan Tangkap. Dep. Pemanfaatan Sumberdaya Perikanan, FPIK-IPB. Bogor.

Manik HM. 2011. Underwater acoustic detection and signal processing near the Seabed. Sonar Systems. Ed ke-1. Croatia: Intechweb. page $255-274$.

Manik, H M. 2012. Seabed identification and characterization using sonar. Hindawi Publishing Corporation Advances in Acoustics and Vibartion. Volume 2012, DOI: $10.1155 / 2012 / 532458$.

Manual Book Operating System Multibeam Echosounder Kongbergs EM 2040C, 2014.

Pujiyati S, Hartati S, Priyono W. 2010. Efek Ukuran butiran, kekasaran, dan kekerasan dasar perairan terhadap nilai hambur balik hasil deteksi hydro akustik. E-Jurnal Ilmu dan Teknologi Kelautan Tropis, Vol. 2, No. 1, Hal. 5967, Juni 2010.

Stanic S, Briggs KB, Fleischer P, Sawyer WB, Ray RI. 1989. High frequency acoustic backscattering froma coarse shell Ocean Bottom. Journal Acoust. Soc.Am., 85,p 125-136.

Training Module Caris Hips \& Sips 9.0 Users Guide, 2014. Canada

Wentworth CK. 1922. A Scale of Grade And Class Terms For Clastic Sediments. Journal of Geology 30: 377-392. 